\title{
İstihbarat Süreci ve İnsan Kaynaklı İstihbaratın Analizi
}

\author{
DOI: $10.26466 /$ opus.773203
}

*

\author{
Ozan Kavsirac1 * \\ * Dr. Öğretim Üyesi, Polis Akademisi Başkanlığı, Ankara / Türkiye \\ E-Posta: ozankavsiraci@gmail.com \\ ORCID: $0000-0001-6351-3725$
}

\section{Öz}

İstihbarat çalışmaları tarih sahnesinin her döneminde güvenlik politikalarının önemli bir unsuru olarak karşımıza çıkmaktadır. Devletlerin kendilerine yönelik olası tehditlere karşı her zaman hazırlıklı olma isteği, istihbarat faaliyetlerini de kaçınılmaz kılmaktadır. İstihbaratın tanımlanmasına yönelik çok sayıda açıklama, istihbarat kavramın bilgi toplama faaliyeti ile ifade etmektedir. Ancak istihbarat faaliyetlerine asıl anlam kazandıran, elde edilen bilgilerin ihtiyaçlar doğrultusunda kullanılmasıdır. Bu noktada istihbarat, bilgi toplamanın yanında toplanan bilgilerin değerlendirilmesi, işlenmesi ve karar alıcı mekanizmalara iletilmesi sürecini kapsamaktadır. Günümüzde tehditlerin çeşitlenerek asimetrik bir boyut kazanması, istihbarat çalısmalarının önemini arttırmakla birlikte istihbarat yöntemlerinin çeşitlenmesini de beraberinde getirmiştir. Güvenlik politikalarında devlet altı unsurların önem kazanmaya başlaması ve teknolojik gelişmelerin sağladığı sayısız imkânlar istihbarat üretimine yönelik süreci de etkilemiştir. İstihbarat faaliyetleri temel olarak, ihtiyaç duyulan bilgilere ulaşılması esasına dayanmaktadır. Bu noktada öncelikli konular, hangi bilgilere gereksinim duyulduğu, nasıl ve ne şekilde bu bilgilere ulaşılacă̆ı önem kazanmaktadır. İhtiyaç duyulan bilgilere ulaşmak için de farklı metotlar kullanılmaktadır. Bu çalışmada istihbarat kavramı ve istihbarat üretim süreci açılanarak istihbarat toplama yöntemleri incelenmiştir. Insan kaynakl istihbarat ile diğer istihbarat toplama yöntemlerinin unsurları değerlendirilmiştir. İnsana dayalı istihbarat yönteminin özellikle hedef unsurların düşünce ve niyetlerinin öğrenilmesinde să̆ladı̆̆ı avantajlar ile yöntemin taşıdı̆̆ı riskler ve sinırlılıklar analiz edilmiştir.

Anahtar Kelimeler: İstihbarat, İstihbarat çarkı, istihbarat toplama metotları, insan kaynakl istihbarat 


\title{
Intelligence Process and Analysis of Human Intelligence
}

\begin{abstract}
Intelligence studies emerge as an significant element of security policies in every stage of the history scene. The desire of states to always be prepared for the possible threats against them makes the intelligence activities inevitable. A large number of explanations for the identification of intelligence are expressed by the activity of information gathering intelligence. However, what gives intelligence activities the real meaning is the use of the information obtained in accordance with the needs. At this point, intelligence includes the process of collecting information as well as evaluating, processing and communicating the collected information to decision-making mechanisms. Nowadays, as the threats are diversified and gain an asymmetric dimension, it increases the importance of intelligence studies and brought about the diversification of intelligence methods. The fact that sub-state elements gained importance in security policies and the many opportunities provided by technological developments also affected the process of intelligence production. Intelligence activities are mainly based on access to the information needed. At this point, priority issues, which information is needed, how and in way to gain access to this information becomes important. Different methods are also used to reach the required information. In this study, the intelligence concept and intelligence production processes are explained and intelligence collection methods are examined. Elements of human intelligence and other intelligence-gathering methods were evaluated. The advantages of the human intelligence method in learning the thoughts and intentions of the target elements and the risks and limitations of the method have been analyzed.
\end{abstract}

Keywords: Intelligence, Intelligence wheel, intelligence gathering methods, human intelligence 


\section{Giriş}

Bir insan hayal edelim ki görme ve işitme duyularından yoksun olsun. Hayal ettiğimiz bu insanın tek başına olası tehlikelerle mücadele etmesinin ve geçimini sağlamasının ne kadar güç olabileceğini tahmin etmek mümkündür. Kaldı ki sağlıklı insanlar dahi hayatların devam ettirmek için birçok hazırlık yapmakta ve kendilerini gelecekteki alternatif durumlara hazırlamak için çalışmaktadırlar. Bu noktada hayatımıza dair imkânlar, ihtiyaçlar ve risklere yönelik bilgi ihtiyacı ön plana çıkmaktadır. Evinize bir televizyon almak istiyorsunuz. Bunun için yapacağınız ilk şey muhtemelen televizyonlar hakkında bilgi toplamak olacaktır. Televizyonlar hakkında bilgi sahibi olan arkadaşlarınıza soracak, internet üzerinden teknik özelliklerini araştıracak ve kendi istediğiniz özellikler ile karşılaştırma yaparak almak istediğiniz televizyona karar vereceksinizdir. Örnekte ifade edildiği üzere hayatımızda alacağımız kararlar öncesinde ilk adım olarak bilgi ihtiyacımızı tatmin etmek için bilgi toplama faaliyetini gerçekleştirmekteyiz. Bilgi toplama faaliyeti hakkında başka bir örnek de günümüzdeki spor müsabakalarıdır. Spor müsabakalarında rakipler karşılaşmadan önce birbirleri hakkında bilgi toplamaktadırlar. Birbirlerinin maçlarını izlemekte, kayıt altına almakta ve özelliklerini detaylı olarak incelemektedirler (Şenel ve Şenel, 2018a, s.15-22). Konuyu devletlerarası ilişkiler olarak düşündügüüüzde, devletlerin bekası ve güvenliği noktasında bilgi toplama faaliyetleri çok daha önemli bir hal almaktadır.

Tarihin ilk dönemlerinde insanlar avlanmak ve kendilerini korumak için iz sürmüşler daha sonra iz sürme yerini keşif faaliyetlerine bırakmıştır. $\mathrm{Bu}$ faaliyeti birey seviyesinden devletler düzeyine çıkardığımızda da benzer bir durumla karşılaşmaktayız. Devletler de kendilerine yönelik olası risk ve tehditlere yönelik bilgi ihtiyacını karşılamak için bilgi toplama ve toplanan bilgileri işleme olarak tanımlanan hayati önem sahip istihbarat faaliyetleri yürütmektedirler (Şenel ve Şenel, 2018a, s.18-19). M.Ö. 500 yıllarında Çinli Sun Tzu'nun "Harp Sanatı" isimli eseri, devlet yönetiminde başarılı olmanın temel vasıtası olarak ön bilgiye sahip olmayı göstermiştir.

İstihbarat faaliyetleri sadece günümüz toplumlarında değil, tarihin her döneminde kendisine yer bulmuştur. Yöntemleri farklılık göstermekle birlikte tarih sahnesinin özneleri her daim kendilerinden habersiz yaşanan gelişmelerden haberdar olma ve olası gelişmelere hazırlanma eğiliminde olmuşlardır. Hz. Musa'nun kavminin yerleşeceği güvenli, verimli ve yerleşik 
yaşama uygun bir yer bulmak amacıyla araştırma yapması ve araştırma sonucu topladığı bilgiler üzerine olası tehditler nedeniyle de 40 yıl kavmi ile birlikte çölde kalması, istihbarat sürecinin önemli bir örneğini oluşturmaktadır (Özdağ, 2014, s.41). Büyük Selçuklu İmparatorluğu'nda vezir Nizamülmülk'ün çevre bölgelere tacirlerin gönderilerek devletin bekasına yönelik tehdit oluşturabilecek gelişmelerden haberdar olunmasını istemesi de istihbarat faaliyetlerinin başka bir örneği olarak karşımıza çıkmaktadır (Özdağ, 2014, s.44). Bilgi ihtiyacından kaynaklanan istihbarat faaliyetlerinin, devlet güvenliği kapsamında iç ve dış tehditlere karşı her zaman hazır olmak ve bu çerçevede doğru milli güvenlik politikalarını tayin etmek için zaruri olduğunu söylemek mümkündür.

19. yüzyıl istihbarat anlayışında önemli gelişmelerin yaşandığı bir süreçtir. İstihbarat faaliyetlerinin sadece savaş zamanlarını değil, barış dönemlerini de kapsamasının gerekliliği üzerinde durulmuştur. 20. yüzyılda yaşanan teknolojik, siyasi, ekonomik gelişmeler ışığında istihbarat faaliyetlerinde modern sürece geçilmiş, 1 ve 2. Dünya Savaşlarında önemli kırılma noktaları yaşanmıştır. SSCB ve ABD'nin oluşturduğu iki kutuplu sistemde devletler, diğer blok içerisinde ve kendi sınırlarında yaşanan gelişmelerden haberdar olma ve bu gelişmelere yönelik önlemler alma noktasında istihbarat faaliyetlerine ağırlık vermişlerdir (Seren, 2016, s.5). Uluslararası ilişkilerde realist güvenlik anlayışının etkili olduğu 2. Dünya Savaşı süresince istihbarat faaliyetlerinin de askeri güç örnekleminde yürütüldüğü görülmektedir.

Günümüzde istihbarat çalışmaları askeri güç boyutundan sıyrılarak teknoloji, ekonomi ve bilimsel gelişmeler ışığında hareket etmeye başlamıştır. Soğuk Savaş'ın sona ermesi ile birlikte güvenlik kavramı klasik görünümünden çıkmış, genişleyerek sektörel boyutlarda değerlendirilmeye başlamıştır. Bu gelişmeler çerçevesinde devletlerarası savaşlar yerini terörizm, çatışma, şiddet gibi kavramlara bırakmaya başlamıştır. Soğuk Savaş Dönemi ürünü olan içerisi/dışarısı ayrımı ortadan kalkmış, devlet altı unsurlar güvenlik ajandalarına dâhil olmuştur. Yeni gelişmeler ışığında devletler artık tek karar verici aktörler olmaktan çıkmış, ideolojiler, kimlikler ve dünya görüşleri, güvenliğin tanımlanma sürecine dâhil olmuştur (Aras, Toktaş ve Kurt, 2010, s.18). Devletler de bu gelişmeler ışığında güvenlik politikalarını, yeni şartlara göre yeniden yapılandırmışlardır. Asimetrik tehditlerin çeşitlenerek ülkeleri hedef almaya başlaması, istihbarat faaliyetlerinin önemini ortaya çıarmıştır. 
$\mathrm{Bu}$ çalışmada istihbarat kavramının analizi yapılarak istihbarat toplama yöntemleri açıklanmış ve insan kaynaklı istihbaratın diğer istihbarat toplama metotları içerisindeki önemi değerlendirilmiştir. Beş bölümden oluşan bu çalışmanın birinci bölümünde istihbarat kavramına yönelik geliştirilen tanımlar incelenmiş, ikinci bölümde istihbarat üretim sürecini ifade eden istihbarat çarkının basamakları açıklanmıştır. Üçüncü ve dördüncü bölümde istihbarat toplama metotları ile insan kaynaklı istihbaratın unsurları değerlendirilmiştir. İnsan kaynaklı istihbaratın tartışıldığı beşinci bölümde ise insana dayalı istihbarat yönteminin sağladığı kazançlar ve bu yöntemin sınırlılıkları ile k1rılgan noktaları analiz edilmiştir.

\section{İstihbarat}

Sosyal bilimler birey ve toplum hayatının çeşitli boyutlarını değerlendirme konusu yaparak inceleme konusu kavramlar üzerinde farklı bakış açları getirmektedir. Toplumsal değişmenin kaçınılmaz olduğu düşünüldüğünde tanımlama yapılmak istenilen kavramlar üzerinde de kesin yargılar geliştirmek güçleşmektedir. İstihbarat kavramı da sosyal bilimlerin bu özelliğinden fazlasıyla etkilenmiştir. Türkçe' de kullandığımız istihbarat kelimesi, Arapça kökenli istihbar ifadesinin çoğulu olup bilgi ve haber anlamlarında kullanılmaktadır (Özdağ, 2014, s.19). Kelime kökeni itibari ile istihbarat, bilgiyi elde etme çabasıdır. Türk Dil Kurumuna göre istihbarat "yeni öğrenilen bilgiler, haberler, duyumlar, bilgi toplama, haber alma" olarak tanımlanmaktadır. İstihbarat kavramını sadece bilgi toplama ile sınırlandırmak hiç şüphesiz yanlış bir tutum olacaktır. Çünkü istihbarat faaliyetlerine anlam kazandıran, elde edilen bilgilerin ihtiyaçlar doğrultusunda kullanılmasıdır. Bu noktada İngilizce'de istihbarat kelimesinin karşılığı olan "intelligence" ifadesinin vurguladığı, toplanan bilgilerin değerlendirilmesi sonucu elde edilen çıktılar önem kazanmaktadır.

İstihbaratın tanımlanmasına yönelik yapılan çok sayıda açıklamanın, kavramın ve istihbarat faaliyetlerinin anlaşılmasını daha da karmaşık bir hale getirdiğini ifade eden Alan Dupont, istihbaratın ne olmadığının ifade edilmesinin önemine vurgu yapmaktadır. Dupont'a göre istihbarat sadece bilgi veya veri değildir. Yukarıda "intelligence" tanımlamasında ifade edildiği üzere Dupont, bilgilerin yorumlanma ve kiymetlendirme süreci sonunda, karar 
alıcı mekanizmalara sunulması, güvenlik politikalarının ve olası operasyonların, bilgilerin işlenmesi ile elde edilen çıktılarla desteklenmesi üzerinde durmaktadır. Bu süreç ile elde edilen ürünler, karar alıcılar için belirsizliklerin ortadan kaldırılmasına hizmet etmektedir.

Hülasa istihbarat, bilgi ve haberlerin toplanmasının yanında ham halinde bulunan bilgi ve haberler üzerinde yorumlama, değerlendirme ve bir sonuca ulaşma faaliyetlerini de kapsamaktadır (Avc1, 2004, s.12). İstihbarat bu tanımı ile birbirini sürekli takip eden bir dizi uygulamayı işaret etmektedir. Bilgilerin toplanması ve toplanan bilgilerin ihtiyaçlar doğrultusunda kullanılması için değerlendirme, yorumlama ve çıktıların karar alıcılara ulaştırılması, başarılı bir istihbarat çalışması için devamlı surette işleyen sistemin parçalarını oluşturmaktadır. Yukarıda ifade edilen hususlar göz önünde bulundurulduğunda istihbaratı, devletlerin kendilerine yönelik faaliyetleri izleyen göz, güvenliklerini hedef alan konuşmaları dinleyen kulak, bekalarını tutan el ve olası ihtimalleri düşünen ve değerlendiren bir beyin olarak ifade edebiliriz (Şenel ve Şenel, 2018a, s.31).

İstihbaratı devletler özelinde değerlendirdiğimizde, bir nevi bağışıklık sistemi olarak ifade etmek de mümkündür. İstihbarat, devletlerin varlığına yönelik olası risklerden önceden haberdar olunarak bu riskleri ortadan kaldırmak ya da muhtemel zararlarına yönelik tedbirler almak için kullanılan bir kalkandır (Kent, 2003, s.10). Bu minvalde devlet çıarlarının korunması, ulusal güvenliğin sürdürülmesine ilişkin bilgilerin toplanması ve değerlendirilmesi işi, uzmanlık ve profesyonellik gerektiren bir yapılanmayı işaret etmektedir.

Devlet güvenliği için zaruri olduğunu değerlendirdiğimiz istihbarat faaliyetlerinin, olası risklerin zamanında belirlenebilmesi, doğru planların ve kaynakların oluşturulması için sahip olması gereken bir takım özellikleri bulunmaktadır. Bu özellikler; doğruluk, kesinlik, sürat, gizlilik, organizasyon ve eğitimli personel kullanılmasıdır. İstihbaratın doğru olmaması, istihbarat elde edememekten daha kötü sonuçlar doğuracağı gibi devlet politikalarının yanlış bilgiler üzerine kurulmasına neden olacaktır.

İstihbaratın kesin olması karar alıcı yöneticilerin doğru kararlar almasına yardımcı olmaktadır. Ucu açık bilgiler, devletlerin olası risklere karşı hazırlıksız yakalanmalarına neden olmaktadır. Faaliyetlerin tespitinde gecikmeler yaşanması, tedbirlerin zamanlamasında hatalara yol açmakta ve tehlikelere karşı savunmasız kalınmasına neden olmaktadır. İstihbarat hizmetlerinde 
kullanılan araç-gereç ve personelin deşifre olmaması, karar alıc mekanizmalara analiz çıktılarının gizlilik kuralları çerçevesinde iletilmesi, istihbarat faaliyetlerinde başarıya ulaşmanın diğer önemli bir unsurudur. Sistematik olarak bilgi toplama, toplanan bilgilerin analiz edilmesi, karar alıcılara ulaştırılması ve bu döngünün koordine edilmesi ancak iş bölümünün olduğu profesyonel bir organizasyon aracılı̆̆ ile mümkün olmaktadır. İstihbarat süreci sonucunda devletleri etkileyen kararlar alınacağı göz önünde bulundurulduğunda, alanında eğitilmiş ve uzman personeller aracılığı ile istihbarat üretim sürecinin desteklenmesi gerekmektedir.

İstihbarat faaliyetleri neticesinde elde edilen çıktılar, ihtiyaçlar doğrultusunda taktik, opersayonel ve stratejik olmak üzere üç temel düzeyde kullanılmaktadır (Seren, 2016: 310). Taktik istihbarat, belirli bir alana ilişkin harekât planı dâhilinde ihtiyaç duyulan bilgiler ile ilgilenmektedir. Muharebe alanında düşmanla ilişkili olarak; düşmanın konumu, yayılma şekli, sayısı, teçhizatı, harekât doktrini, lojistik durumu ve morali taktik istihbaratın ilgi duyduğu faktörlerdir (Şenel ve Şenel, 2018b, s.23-24). Operasyonel istihbarat, belirli bir harekât alanına odaklanmaktan ziyade düşmanın niyeti üzerine tahminler geliştirmeye yardımcı olacak daha geniş bilgilere ihtiyaç duymaktadır. Askeri güce ilişkin bilgiler yanında sosyal, ekonomik ve siyasi konulara ilişkin çalışmaları da kapsamaktadır. Stratejik istihbarat, taktik ve operasyonel istihbarata göre daha geniş bir çalışma sahasını ve zaman dilimini kapsamaktadır. Savaş ve barış dönemleri de dâhil olmak üzere ulusal ve uluslararası alanda güvenlik aktörlerinin kabiliyeti, zaafları ve niyetleri konusunda tahminler geliştirmek için askeri, ekonomik, siyasi, demografik ve kültürel konularda bilgilerin toplanması ve işlenmesi faaliyetlerini kapsamaktadır.

\section{İstihbarat Çark1}

İstihbarat faaliyetlerinin tanımı yapılırken bilginin toplanması ve işlenmesi çerçevesinde birbirini takip eden bir dizi uygulama üzerinde durulmaktadır. Bilgi toplamak, istihbaratın vazgeçilmez bir parçası olmakla birlikte analizi yapılarak kıymetlendirilmeyen bilginin ihtiyaçlara cevap vermesi de mümkün değildir. İstihbarat çarkı, bilgi toplama, toplanan bilgileri analiz etme, kıymetlendirme ve karar alıcı mekanizmalara ulaştırma sürecini kapsamaktadır. Farklı faaliyetlerin yürütüldügü çeşitli basamaklardan oluşan istihbarat 
çarkı, aktörlere göre farklılık gösterebilse de bilginin işlenerek ihtiyaçlar doğrultusunda çıktılar elde etme amacı, sistemin temelini oluşturmaktadır. ABD ve Türkiye' de benzerlik gösteren istihbarat çarkının basamaklarını, istek-ihtiyaç, planlama-yönlendirme, bilgilerin toplanması, tasnif-işleme, analiz-üretim ve dağıtım olmak üzere altı başlık altında ifade etmek mümkündür (Acar, 2011, s.170-184 ve Özdağ, 2014, s.371).

İstihbarat faaliyetleri, savaş ve barış dönemlerinde devamlı olarak işlemektedir. Bu noktada karar alıcı mekanizmaların ihtiyaçları önem kazanmaktadır. Karar alıcıların belirlediği ihtiyaçlar istihbarat faaliyetlerine rehberlik etmektedir. İstihbarat ürünlerinin politikaya dönüştürülmesinde, sürecin ilk basamağı olan istek-talebin açık bir şekilde bildirilmesi önem kazanmakta ve çarkın doğru işlemesine katkı sağlamaktadır. İstihbarat çarkının ikinci basamağı, toplanacak bilgilere ilişkin bir yol haritasının oluşturulmasıdır. Bu aşamada, ihtiyaç duyulan bilgilerin hangi kaynaklardan ne şekilde elde edileceği, bilgilerin niteliği ve bilgi toplama faaliyetlerinde dikkat edilmesi gereken hususlar önem kazanmaktadır. İstihbarat faaliyetleri sınırlı kaynaklarla yürütülmektedir. Bu nedenle ihtiyaçlar çerçevesinde geliştirilecek planlama ve yönlendirme, kaynakların da verimli ve etkin bir şekilde kullanılmasını sağlamaktadır.

İstihbarat faaliyetlerinin en önemli ve riskli aşaması olan bilgilerin toplanması, istihbarat çarkının üçüncü basamağını oluşturmaktadır. Planlama aşamasının rehberliğinde yürütülen bilgi toplama faaliyetleri, bir sonraki bölümde açıklanan metotlar kullanılarak yürütülmektedir. Bilgilerin toplanma sürecinin hızlı işlemesi ve toplanan bilgilerin ihtiyaçlara cevap verecek nitelikte olması, doğru politikaların hayata geçirilmesi için oldukça önemlidir.

Bilgilerin tasnifi-işleme aşaması, bilgi toplama aşamasında elde edilen ve dağınık halde bulunan bilgilerin dosyalanarak sınıflandırılması esasına dayanmaktadır (Özdağ, 2014, s.386). Tasnif işleminde konularına göre düzenlenen bilgiler, analiz sürecini kolaylaştırmaktadır. İstihbarat faaliyetlerinde toplanan bilgilere anlam kazandırılan aşama analiz-üretim basamağıdır. Tasniflenen bilgilerin doğruluğunun teyit edilerek gizli faaliyetlerin aydınlatılması, düşman unsurların düşüncelerinin çözümlenmesi bu aşamada gerçekleştirilmektir (Yılmaz, 2007, s.140). Analiz süreci ile ihtiyaç duyulan konularda istihbarat üretimi sağlanarak karar alıcılara raporlar hazırlanmaktadır. Analiz aşamasında elde edilen çıktıların net ifade ve tespitler içermesi önemlidir. Bu sebeple analiz sürecinde görev yapan uzmanların hedeflerle ilgili 
tüm özellik ve yeteneklere hâkim olması gerekmektedir (Demirbaş, 2017, s.39). Dağıtım aşaması, istihbarat ürününün karar alıcılara güvenilir yollar kullanılarak ulaştırılmasıdır.

\section{İstihbarat Toplama Yöntemleri}

İstihbarat faaliyetlerinin temeli, ihtiyaç duyulan konuları aydınlatacak bilgilere ulaşılması esasına dayanmaktadır. Bu noktada öncelikli konular, hangi bilgilere gereksinim duyulduğu, nasıl ve ne şekilde bu bilgilere ulaşılacağ önem kazanmaktadır. İhtiyaç duyulan bilgilere ulaşmak için üç farklı metot kullanılmaktadır. Bunlar; insan istihbaratı, teknik istihbarat ve açık kaynak istihbaratıdır.

İnsan istihbaratı, istihbarat faaliyetleri ile ilgili eğitim almış profesyonel bireyler aracılığı ile hedef unsurların niyetleri, kapasiteleri, imkânları konusunda görsel ve işitsel yollarla bilgilerin toplanarak analiz edilmesi sonucu elde edilen istihbarat olarak tanımlanmaktadır. Bilgi toplama aracı insan olmakla birlikte istihbarat kaynağının belge, kayıt veya insan olması mümkündür. İnsan istihbaratının tarihte bilinen en iyi örneği Thomas Edward Lawrence' dır. Arapça 'ya ve İslam dinine hâkim olan Lawrence Arabistan'da birçok faaliyet yürütmüştür (T1lısbık ve Akbal, 2006, s.98).

Teknik istihbarat, bilgi toplama faaliyetlerinin teknolojinin sunduğu imkânlar doğrultusuna teknik araçlar kullanılarak yürütülmesi ve analiz edilmesidir (Özdağ, 2014, s.134). Teknik istihbarat, elektromanyetik verilerin ve iletişim araçlarının takibi yoluyla kayıt altına alınması şeklinde gerçekleştirilmektedir. Bu kapsamda sinyal, görüntü, elektronik araçlar, uydu vb. unsurlar kullanılmaktadır. Günümüzde teknolojinin hayatımızın her alanına girmeye başlaması, istihbarat yöntemlerinin de teknik olarak gelişimini beraberinde getirmektedir.

Açık kaynaklar, istihbarat faaliyetlerinin en önemli kaynağını oluşturmaktadır. İstihbarat faaliyetleri sonucu ulaşılan bilgilerin \%75 ile \%90'1 açık kaynaklardan temin edilmektedir (Holt, 1995, s.57). Açlk kaynaklar, bireylerin ulaşımına açık yazılı veya sözlü her türlü bilgi, belge veya haberlerden teşkil etmektedir. Bu kapsamda açık kaynak istihbaratının kaynağını, internet, medya organları, konferanslar, yazılı yayınlar, coğrafi bilgiler vb. oluşturmaktadır. Açı kaynaklar üzerinden bilgi toplamak önemli zorluklar da içermektedir. Çünkü açk kaynaklar içerisinde çok sayıda yanıltıcı ve yanlış 
bilgiler de bulunmaktadır. Bu noktada bilgileri analiz eden uzmanlara doğru ve yanlış bilginin ayırt edilmesinde önemli görevler düşmektedir. Hayatımızın büyük bir parçası durumuna gelen sosyal medya, istihbarat toplama yöntemlerinin önemli bir kaynağı haline gelmektedir.

\section{İnsana Dayalı (Kaynaklı) İstihbarat}

İnsana dayalı istihbaratın temeli beşeri kaynaklara dayanmaktadır. Kaynak kelimesi, istihbarat faaliyetlerinde çok yönlü kullanılan bir kavramdır. Kaynak genel bir ifade ile haber vasitası olarak ifade edilmektedir. İnsana dayalı istihbarat faaliyetleri, insanlarla kurulan temas sonucunda elde edilen bilgileri işaret etmektedir. İnsana dayalı istihbarat faaliyetleri, istihbarat teşkilatlarının kendi kadrolu personelleri aracılığı ile yerine getirilebileceği gibi ihtiyaç duyulan bilgilere erişim olanağı bulunan diğer kişiler aracılığı ile de yürütülmektedir. Bu çerçevede statüleri noktasında bilgi kaynaklarını, kadrolu personel, ajan, mutemet, muhbir, itirafçı, gizli soruşturmacı veya münferit bilgi kaynakları olarak ifade etmek mümkündür (Urhal, 2008, s.222).

Kadrolu personel, istihbarat teşkilatlarında istihbarat faaliyetlerinin yürütülmesinden sorumlu, devlet memurları kanunu kapsamında değerlendirilen kişilerden oluşmaktadır. Kadrolu personel, istihbarat teşkilatlarında çal1şabilecek kriterlere sahip olan kişiler arasından seçilerek belirli bir eğitime tabi tutulmaktadırlar. Kadrolu personel öğrendikleri bilgileri, kişisel değerlendirmelerden uzak bir şekilde not ederek tasnif birimlerine iletmektedirler. Öğrenilen bilgilerin basit ve saf hali ile iletilmesi doğru değerlendirmelerin yapılabilmesi için önem arz etmektedir.

Ajanlar, hedef durumunda bulunan kişi ya da örgütlere ilişkin çalışmalarda yararlı olacağı düşünülen ve bu çerçevede yönlendirilen kişilerden oluşmaktadır. Ajanların faaliyetleri aynı zamanda espiyonaj olarak da tanımlanmaktadır. Ajanlar, kadrolu personelin gözetimi altında, bir menfaat karşılığında suçörgütleri ve suç faaliyetleri hakkında bilgi veren ve olası tehditlerin aydınlatılmasına yardım eden kişilerdir (Holt, 1995, s.69). Ajanların gizli faaliyetleri için görev yapacağ geliştirilmektedir. Ajanlar için yeni bir kimlik ve yaşam hikâyesi oluşturma işlemi, maskeleme olarak tanımlanmaktadır. Maskeleme, resmi bir görevde çalışmak üzere yapılabileceği gibi gayri resmi bir hayat hikâyesinin geliştirilmesi de mümkündür. Ajanlar, kadrolu personelin yönlendirmesi ile hareket 
etmeleri noktasında muhbirlerden ayrılmaktadırlar. Ajanlar, gizli faaliyetleri sevk ve idare eden ve kendilerinden sorumlu, case officer olarak tanımlanan kadrolu personel ile iletişime geçmektedirler. Ajanların kendilerinden sorumlu kadrolu personele bilgi akışının sağlanması için posta, radyo ve televizyon gibi cansız aracılar kullanılabileceği gibi birbirlerini tanımayan aracı bir ajanın da kullanılması mümkündür (Şenel ve Şenel, 2018a, s. 97-98).

Mutemet, ajanların aksine örgüt faaliyetleri içerisinde bulunmayan fakat hedef konumda bulunana kişi ya da örgütlerin faaliyetleri hakkında danışılan güvenilir kişilerdir. Mutemetler, belirli aralıklarla ihtiyaç duyulan konularda kadrolu personele bilgi sağlamaktadırlar (Urhal, 2008, s.223). Bir suç bölgesinde mesleki faaliyet yürüten esnaflar, bu kategoriye örnek oluşturmaktadır.

Muhbirler, örgüt faaliyetleri kapsamında düzenli aralıklarla olmamakla birlikte bilgi sahibi oldukları dönemlerde kadrolu personele kendi isteği ile bilgi sağlayan kişilerdir. Muhbirler, gönüllü muhbirler, ücretli muhbirler ve amaçlarını gizleyen muhbirler olarak üç kategori de tasniflenmektedir (Urhal, 2008, s.224-225). Gönüllü muhbirler suç örgütleri veya faaliyetleri içerisinde bulunan ve bir menfaat talep etmeden suç faaliyetleri ya da suç faaliyetlerini aydınlatacak deliller hakkında kadrolu personele bilgi sağlayan kililerdir. Ücretli muhbirler, gönüllü muhbirler için ifade ettiğimiz bilgi akışı için para talep eden kişilerdir. Amaçlarını gizleyen muhbirlerin bilinen en iyi örneği intikam alma güdüsü ile hareket eden kişilerdir. Hedefler hakkında sağladığı bilgi karşılığında para talebinde bulunmamaktadırlar.

İtirafçı, içinde bulundukları suç örgütlerinin faaliyetleri hakkında güvenlik hizmeti sunana kadrolu personele açık olarak bilgi veren kişilerdir. Bu kişiler, verdikleri bilgilerin niteliğine göre yasaların sunmuş olduğu pişmanlık indiriminden faydalanmaktadırlar. Bu kişiler bilgi akışı sağladıkları örgütler tarafından hedef konumuna geldikleri için genel olarak savcllı tarafından bilgileri alınıp gerek duyulduğu takdirde kendilerine koruma sağlanmaktadir.

Gizli soruşturmacı, kimliğini gizleyerek suç örgütleri içerisinde kendini kabul ettirip, suç faaliyetleri hakkında bilgi toplayan, suçların önlenmesi ve aydınlatılması noktasında güvenlik hizmeti sunan personele yardımcı olan kişilerdir. Gizli soruşturmacilar genel olarak güvenlik hizmeti sunana kamu 
görevlileri arasından seçilmektedir. Gizli soruşturmacı olan kamu görevlilerinin deşifre olması durumunda hayati tehlikelere maruz kalmaları mümkün olduğu için bu yöntem pratikte çok kullanılmamaktadır (Urhal, 2008, s.227).

Münferit bilgi kaynakları, hedef kişi ya da örgütler hakkında toplumun içerisinde bilgi akışı sağlayan her hangi bir kişiyi (seyyar satıcılar, market çalışanları, kuaförler, işletmeciler vb.) ifade etmektedir. İnsana dayalı bilgi kaynakları yukarıda açıklandığı üzere hedef kişi, örgüt ya da faaliyetler hakkında bilgi alınana bireyleri ifade etmektedir. Bu kişiler bilgi akışının sağlanmasında kamu görevlisi olma, kamu görevlileri tarafından yönlendirilme ya da bir menfaat karşılığında bilgi akışı sağlama noktalarında birbirlerinden ayrilmaktadırlar.

\section{İnsana Dayalı (Kaynaklı) İstihbaratın Analizi}

İstihbarat toplama metotlarından teknik ve açık kaynak istihbaratı günümüzde teknolojinin gelişmesi ile birlikte yoğun olarak kullanılmaktadır. Ancak hedef unsurlar üzerinde detaylı bilgilerin elde edilerek gerekli tedbirlerin alınması ve olası tehditlerin aydınlatılması noktasında insan kaynaklı istihbarat anahtar rol oynamaktadır. Tarihin her döneminde insan istihbaratının önemi birçok defa vurgulanmıştır. Bu noktada Napolyon'un "doğru ve yerinde kullanılan bir casus savaşta iki yüz bin kişiye bedeldir." (Şenel ve Şenel, 2018a, s.67) ve Sun Tzu'nun "casuslar kullanarak başarlar elde etmek, zeki bir devlet yöneticisinin ve başarıl bir ordu komutanm işidir."(Tzu, 2009, s.72) sözleri insana dayalı istihbarata verilen önemi göstermektedir. ABD'nin Vietnam Savaşı'nda tüm teknolojik araç-gereç ve silahlarına rağmen başarılı olamamasının temel sebebini insan istihbaratındaki yetersizlik olarak göstermek mümkündür. Sahadaki insanların köylü, casus veya savaşçı olabilme noktasındaki ayrımın net olarak yapılabilmesi için insan kaynağı, temel faktör olarak karşımıza çımaktadır.

Günümüzde terörle mücadele politikaları çerçevesinde insan kaynaklı istihbarat; terör grupları içerisine eleman sızdırma, teslim olan örgüt üyelerinin itirafçı olması ve muhbirlerin örgüt faaliyetleri hakkında bilgi sağlaması kapsamında kullanılmaktadır. Terörist grupların içerisine eleman sızdırılması önemli avantajlar sağlamasının yanında hayati tehlikeler de içermektedir. Bu sebeple terörist grupların içerisine eleman sızdırılması en son başvurulan yöntemdir. Terör örgütlerinin faaliyetleri ve planlarının aydınlatılması, bu 
çerçevede bilgi ve belgelerin deşifre edilmesi ve yer gösterme operasyonlarında daha çok teslim olan itirafçılardan yararlanılmaktadır. Günümüzde terör örgütlerinin motivasyon kaynakları ve harekat planları hakkında bilgi sahibi olmak, olası terör faaliyetlerini önlemede temel faktördür. İnsan istihbaratı dışında kalan diğer istihbarat toplama metotları, hedef unsurların niyetleri hakkında bilgi akışı sağlamada yetersiz kalmaktadır. Bu nedenle hedef unsurların düşünceleri ve niyetlerinin tespit edilmesi kapsamında insan kaynağının kullanılmasına ihtiyaç duyulmaktadır. Bu noktada 11 Eylül saldırılarını, istihbarat toplama metotlarından insan kaynağında yaşanan eksikliğin bir sonucu olarak görmek mümkündür. Teknik istihbarat olarak güçlü bir konumda bulunan ABD istihbaratı, 11 Eylül saldırılarını önlemede yetersiz kalmıştır. İnsan istihbaratının sağladığı katkıları aşağıdaki şekliyle ifade etmek mümkündür.

İnsan istihbaratı, hedef unsurların yakın, orta ve uzun vadedeki amaçları ve planları hakkında bilgi sağlamaktadır. Diğer istihbarat toplama metotları harekete geçmiş ve kayıt altına alınmış faaliyetler hakkında bilgi sağlarken insan istihbaratı, gelecekteki muhtemel konular üzerinde bilgi akışı sağlamaktadır. Karar alıcı mekanizmalar için olası tehditlere yönelik tedbirlerin acil bir şekilde alınmasının önem taşıdığı göz önünde bulundurulduğunda, insan kaynaklı istihbaratın erken ikaz sistemi gibi çalışması tedbirlerin zamanında alınması için önemli avantajlar sağlamaktadır. Ayrıca teknik ve açık kaynak istihbaratı ile temin edilen ve teyide muhtaç bilgilerin doğrulanmasında ve öncelik sıralamasının yapılmasında insan kaynaklı istihbarat kullanilmaktadir.

İnsan kaynaklı istihbarat, her türlü koşulda kullanılabildiği gibi herhangi bir teknolojik altyapıya ihtiyaç duymamaktadır. Bireyler arası iletişim ön planda olduğu için hava, arazi, teknoloji vb. faktörlerden etkilenmemektedir. İnsan istihbaratının teknolojik araç-gereç ve altyapıya ihtiyaç duymaması mali olarak da önemli avantajlar sağlamaktadır. İnsan istihbaratının teknik koşullardan bağımsız olarak kullanılabilmesi esnekliği de beraberinde getirmektedir. İnsan kaynağının yeni koşullara hızlı bir şekilde ayak uydurabilmesi, ani hedef değişikliğinde bulunabilmesi ve hızlı bilgi temin edebilmesi mümkündür.

Hedef unsurların ideolojileri ve bağlı bulundukları ideolojilere yönelik iddiaları hakkında bilgi sahibi olmak ve öngörüler geliştirmek insan istihbaratı 
ile mümkün olmaktadır. Diğer istihbarat toplama metotları sadece maddi unsurlar üzerinden çıkarımlar yapmaya imkân sağlarken, insan kaynaklı istihbarat normatif unsurların değerlendirilmesini mümkün kılmaktadır. İnsan istihbaratının askeri operasyonların yanında asimetrik tehditlere yönelik olarak da kullanılabilmesi önemli bir avantaj olarak karşımıza çıkmaktadır.

İnsan kaynaklı istihbarat, devlet güvenliğinin sağlanmasında önemli avantajlar sunarken yetersiz kaldığı ve insanların duygusal yaradılışının gereği yanılabildiği noktaları da bulunmaktadır. Ajanların hedef unsurların güvenini kazanabilmesi uzun bir süreç gerektirmektedir. Güvenliğe ilişkin konularda hızlı kararlar alınması gerektiğinden uzun bekleyişler devletleri zor durumda bırakabilmektedir. Ajanların deşifre olma riskleri de her zaman göz önünde bulundurulmalıdır. Ayrıca ajanların kontrol altında tutulmalarının mümkün olmadığı durumlarda çift taraflı çalışmaları karşılaşılan bir durumdur. Bu noktada güvenliğe ilişkin konularda yapılan çalışmaların, istihbarat çalışmaları yürüten devletin aleyhine işlediği görülmektedir (Özdağ, 2014, s.129).

İnsan kaynaklı istihbarat yönteminde bilgi akışının güvenliği için haber sağlayan kaynaklar ile sürekli iletişim halinde bulunulması gerekmektedir. Aksi halde iletişimin sınırlı tutulduğu durumlarda, haber kaynaklarının devlet aleyhine faaliyetlerde bulunma riski ortaya çıkmaktadır. Hülasa insan kaynaklı istihbaratta kontrol mekanizmasının üst seviyede tutulması gerekmektedir.

İnsan kaynaklı istihbarat yönteminde, haber kaynağı tarafından temin edilen bilginin, değerlendirilerek doğruluğunun teyit edilmesi gerekmektedir. Ajanların doğru bilgileri aktardığına yönelik her zaman şüphe ile hareket edilmelidir. Ajanların sağladığı bilgilere yönelik şüphenin aydınlatılması da istihbarat sürecini yavaşlatmaktadır. İnsan kaynaklı istihbarat yöntemi; hedef örgütler içerisine ulaşmanın mümkün olmadığı, ideolojik ve manevi faktörler nedeniyle haber kaynağı devşirmenin yapılamadığı durumlarda kullanılamamaktadır.

Hedef bölge ve örgütlere yönelik insan kaynaklı istihbaratın kullanılabilmesi için bölge ve örgüt kültürünü, yapısını ve dilini bilen insan kaynağı gerekmektedir. Bu noktada hedef unsurların maddi ve manevi değerlerini bilen insan kaynağının bulunması ve eğitilmesi başarılı istihbarat çalışmaları için ön koşuldur. 
İstihbarat çalışmalarının hedefi olan örgütlerde, bilgi akışı sağlayan kaynakların suç faaliyetlerine karışması durumu, meşruluk noktasında sorunlar ortaya çıkarmaktadır. Bu noktada yasal mevzuatın uygulanması cezai sorumluluğu gerektirmektedir. Ayrıca istihbarat personeli ve teşkilatları zor durumda kalmaktadır.

\section{Sonuç ve Tartışma}

Temel aktörlerin devletler olduğunu ifade eden realizmin temelinde, anarşinin hâkim olduğu uluslararası sistemde devletlerin bekası için silahlanma yarışı bulunmaktadır. Silahlanma yarışına benzer bir durum da devletlerin güvenliklerini sağlamak için yürüttüğü istihbarat faaliyetleri ve icatlarında gözlemlenmektedir. Bu yarış, yeni istihbarat metotları ve yöntemlerinin gelişimine hız kazandırmış ve günümüze kadar gelişerek gelmiştir. İstihbarat sadece silahlı kuvvetler tarafından kullanılan bir araç olmaktan çıkmış, karar vericilerin de sürece dâhil olduğu bir güvenlik aracına dönüşmüştür. İstihbarat faaliyetlerinin etkin kullanımı ve akademik bir disiplin haline gelmesi, İkinci Dünya Savaşı'ndan sonra realizmin hâkim olduğu döneme rastlamaktadır. Bu dönemde istihbarat faaliyetleri, istihbarat toplama yöntemleri ve karşı istihbarat sıkça tartışılarak, istihbaratın hem teoride hem de pratikte gelişimine katkı sağlamıştır.

Günümüzde devletlerin güvenlikleri için istihbarat vazgeçilmez bir unsur olarak karşımıza çıkmaktadır. Bu sebeple, devletler her yıl bütçelerinden önemli oranda istihbarat faaliyetlerine ve istihbarat tekniklerinin geliştirilmesine pay ayırmaktadır. İstihbarat faaliyetleri için bilgiyi temin etme önemli bir rol oynamaktadır. Bu kapsamda bilgi toplama için temel olarak üç farklı istihbarat toplama yöntemi bulunmaktadır. Bunlar; insana dayalı istihbarat, teknik istihbarat ve açık kaynaklı istihbarat toplama yöntemleridir. Bahse konu istihbarat toplama yöntemlerinin kazançlarının yanında, istihbarat sürecini olumsuz etkileyebilecek zorlukları da bulunmaktadır. Açık kaynaklar, istihbarat faaliyetlerinin en önemli kaynağını oluşturmaktadır. İstihbarat faaliyetleri sonucu ulaşılan bilgilerin \%75 ile \%90'1 açık kaynaklardan temin edilmektedir. Açık kaynaklardan bilgi toplama metodu olarak da teknolojik gelişmelerin sağladığı araç ve gereçlerden faydalanılmaktadır. Teknik istihbarat, teknolojik cihazların kullanıldığı tüm istihbarat yöntemlerini kapsa- 
maktadır. Açık kaynakların ve teknolojinin sağladığı imkânlara rağmen istihbarat faaliyetlerinde insan unsuru her zaman önemini korumaktadır. Çünkü insan kaynaklı istihbarat, rakip unsurların gerçek niyetlerinin tespit edilmesinde anahtar rol üstlenmektedir. Ayrıca sahadaki insanların köylü, casus veya savaşçı olabilme noktasındaki ayrımın net olarak yapılabilmesi için insan kaynağı, temel faktör olarak karşımıza çıkmaktadır.

Açık kaynak ve teknik istihbarat toplama metotları harekete geçmiş ve kayıt altına alınmış faaliyetler hakkında bilgi sağlarken insan istihbaratı, gelecekteki muhtemel konular üzerinde bilgi akışı sağlamaktadır. Ayrıca teknik ve açık kaynak istihbaratı ile temin edilen ve teyide muhtaç bilgilerin doğrulanmasında ve öncelik sıralamasının yapılmasında yine insan kaynaklı istihbarat kullanılmaktadır. İnsana dayalı istihbaratın teknik koşullardan bağımsız olarak kullanılabilmesi, esnekliği de beraberinde getirmektedir. İnsan kaynağının yeni koşullara hızlı bir şekilde ayak uydurabilmesi, ani hedef değişikliğinde bulunabilmesi ve huzlı bilgi temin edebilmesi mümkündür. Diğer istihbarat toplama metotları sadece maddi unsurlar üzerinden çıkarımlar yapmaya imkân sağlarken, insan kaynaklı istihbarat, normatif unsurların değerlendirilmesini mümkün kılmaktadır.

İnsan kaynaklı istihbarat, devlet güvenliğinin sağlanmasında önemli avantajlar sunarken yetersiz kaldığı ve insanların duygusal yaradılışının gereği yanılabildiği noktaları da bulunmaktadır. Özellikle ajanların kontrol altında tutulmalarının mümkün olmadığı durumlarda çift taraflı çalışmaları karşılaşılan bir durumdur. Bu noktada güvenliğe ilişkin konularda yapılan çalışmaların, istihbarat çalışmaları yürüten devletin aleyhine işlemesi mümkündür. Bu nedenle insan kaynaklı istihbaratta kontrol mekanizmasının üst seviyede tutulması gerekmektedir. Hedef bölge ve örgütlere yönelik insan kaynaklı istihbaratın kullanılabilmesi için bölge ve örgüt kültürünü, yapısını ve dilini bilen insan kaynağı gerekmektedir. Bu noktada hedef unsurların maddi ve manevi değerlerini bilen insan kaynağının bulunması ve eğitilmesi başarılı istihbarat çalışmaları için ön koşulu oluşturmaktadır.

İstihbarat faaliyetlerinin tarihsel gelişiminde insan kaynağı her türlü teknolojik gelişmelere ve olumsuzluklarına rağmen önemini korumaktadır. Günümüzde elde edilen bilgilerin çoğunlukla kaynağı açık kaynaklar ve teknik istihbarat olmasına rağmen, insan kaynağının özellikle sahada sağladığı kolaylıklar ve rakip unsurların gerçek niyetlerinin belirlenmesindeki rolü, vazgeçilmez bir istihbarat toplama yöntemi olmasını sağlamaktadır. 


\section{EXTENDED ABSTRACT}

\section{Intelligence Process and Analysis of Human Intelligence}

\section{Ozan Kavsirac1 \\ Police Academy}

Intelligence activities have found its place not only in today's societies, but also in every period of history. Although their methods differ, the subjects of the history scene have always tended to be aware of the developments that have occurred unaware of them and prepare for possible developments. It is possible to say that intelligence activities arising from the need for information are essential to always be ready for internal and external threats within the scope of state security and to determine the right national security policies within this framework.

The 19th century is a period of significant developments in intelligence understanding. It was emphasized that intelligence activities should cover not only war times, but also periods of peace. In light of the technological, political, economic developments in the 20th century, intelligence activities have been passed to the modern process, and there have been significant breakpoints in World Wars 1 and 2. Today, intelligence studies have begun to move in the light of technology, economy and scientific developments by getting rid of the military power. Along with the end of the Cold War, the concept of security has emerged from its classic outlook, expanded to be evaluated in sectoral dimensions.

Limiting the concept of intelligence only to information gathering will undoubtedly be the wrong attitude. Because it is the use of the information obtained in accordance with the needs that make sense of intelligence activities. Intelligence includes not only the collection of information and news, but also the activities of interpreting, evaluating and reaching a conclusion on the information and news in the raw state. Intelligence points to a series of applications that continuously follow each other with this definition. The collection of information and the use of the collected information in accordance with the needs of the assessment, interpretation and output to the decision makers 
constitutes the parts of the system that are continuously functioning for successful intelligence work.

The basis of intelligence activities is based on accessing information to illuminate the topics needed. At this point, priority issues, which information is needed, how and in what way to access this information become important. Three different methods are used to access the information needed. These are human intelligence, technical intelligence and open source intelligence. Human intelligence is defined as intelligence obtained by collecting information about the objectives, capacities, opportunities of the target elements through professional individuals who are trained in intelligence activities, and by gathering information in visual and auditural ways. Technical intelligence is the execution and analysis of information collection activities using technical tools in the direction of the possibilities offered by technology. Technical intelligence is carried out in the form of recording electromagnetic data and communication tools through monitoring. Open resources are the most important source of intelligence activities. $75 \%$ to $90 \%$ of the information obtained as a result of intelligence activities is obtained from open sources. Open sources are all kinds of information, documents, or news that are written or oral in the reach of individuals.

The basis of human intelligence is based on human resources. The word source is a multifaceted concept in intelligence activities. The source is expressed as a news event with a general expression. Human-based intelligence activities point to the information obtained as a result of contact with people. Human-based intelligence activities can be carried out through the intelligence agencies' own staff, as well as through other people who have access to the information needed. In this context, it is possible to express information sources at the point of their status as staff personnel, agents, trustees, informants, confessors, secret investigators or individual sources of information.

Today, having information about the motivational resources and operational plans of terrorist organizations is the fundamental factor in preventing possible terrorist activities. Other intelligence-gathering methods outside human intelligence are insufficient to provide information about the intents of target elements. Therefore, the use of human resources is needed to determine the thoughts and intentions of the target elements. Human intelligence, as it can be used under all conditions, does not need any technological infrastructure. Since communication between individuals is at the forefront, it 
does not affected by the air, terrain, technology etc. factors. It also provides significant benefits in the financial sense that human intelligence does not need technological tools and infrastructure. It is possible with human intelligence to have information about the ideologies of the target elements and their claims regarding the ideologies to which they belong and to develop forecasts. While other intelligence gathering methods can only be used to make inferences over material elements, human-source intelligence makes it possible to evaluate the normative elements. It is an important advantage that human intelligence can also be used for asymmetric threats in addition to military operations.

While human-sourced intelligence offers significant advantages in ensuring state security, there are also points where it is inadequate and people can be mistaken due to their emotional creation. In human intelligence method, it is necessary to keep in touch with the sources that provide news for the security of the information flow. Otherwise, in cases where communication is limited, there is a risk that news sources will operate against the state. In order to use human-sourced intelligence for target regions and organizations, a human resource that knows the region, organizational culture, structure and language is required. At this point, finding and training the human resource that knows the material and spiritual values of the target elements is a prerequisite for successful intelligence work.

In the historical development of intelligence activities, the human resource is maintaining its importance despite all kinds of technological developments and negativities. Although the sources obtained today are mostly sources of open sources and technical intelligence, the convenience of human resources in the field and its role in determining the true intentions of competitors make it an indispensable intelligence gathering method.

\section{Kaynakça / References}

Acar Ü., (2011), İstihbarat. 1. Baskı, Ankara: Akçă̆ Yayınları.

Aras, B., Toktaş, Ş., ve Kurt, Ü. (2010). Araştırma merkezlerinin yükselişi: Türkiye'de dış politika ve ulusal güvenlik kültürüu. (SETA) Siyaset, Ekonomi ve Toplum Araştırmaları Vakfı.

Avc1, G., (2004), İstihbarat teknikleri. 1. Baskı, İstanbul: Timaş Yayınları. 
Demirbaş, M. (2017). İstihbaratın tarihsel gelişiminde Türkiye ve ABD Karşılaştırılması. Yayınlanmamış Yüksek Lisans Tezi, Polis Akademisi Başkanlığı, Güvenlik Bilimleri Enstitüsü, Ankara.

Holt M. P. (1995). Secret intelligence and public policy. United States of America: Congressional Quarterly.

Kent S., (2003). Stratejik istihbarat. Özbek, Y. B. ve Arıca, Ş., N. (çev.), 3. Baskı, Ankara: Asam Yayınları.

Özdağ Ü. (2014), İstihbarat teorisi. 8. Baskı, Ankara: Kripto Yayınları.

Seren, M., (2016). Stratejik istihbaratın güvenlik stratejileri ve politikaları açısından yeri ve önemi. Yayınlanmamış Doktora Tezi, Ankara: Polis Akademisi.

Şenel, M. ve Şenel, T. A. (2018a). Temel güvenlik konularımız. 2. Baskı, Ankara: Polis Akademisi Yayınları.

Şenel, M. ve Şenel, T. A. (2018b). Stratejik istihbarat. 2. Baskı, Ankara: Polis Akademisi Yayınları.

Tilısbık N. ve Akbal Ö. (2006), İstihbarat ve Türkiye. 1. Baskı, Konya: İKİA Yayıncilik.

Tzu, S. (2014). Savaş sanatı. Otkan, P. Ve Fidan, G. (çev.), 1. Baskı, İstanbul: İş Bankası Kültür Yayınları.

Urhal, Ö. (2008), Kamu güvenliği açısından istihbarat ve örgütlü suçlar. 1. Baskı, Ankara: Adalet Yayınları.

Yılmaz S., (2007), 21. yüzyılda güvenlik ve istihbarat, 1. Baskı, İstanbul: Milenyum Yayınları.

\section{Kaynakça Bilgisi / Citation Information}

Kavsıracı, O. (2020). İstihbarat süreci ve insan kaynaklı istihbaratın analizi. OPUS-Uluslararası Toplum Araştırmaları Dergisi, 16(27), 700719. DOI: 10.26466/opus.773203 